\title{
A CASE OF UNILATERAL TIBIAL HEMIMELIA WITH UNILATERAL RADIAL CLUB HAND AND CONSTRICTIVE BAND
}

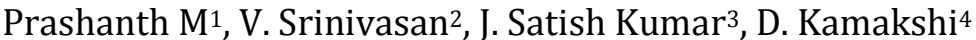

\section{HOW TO CITE THIS ARTICLE:}

Prashanth M, V. Srinivasan, J. Satish Kumar, D. Kamakshi. "A Case of Unilateral Tibial Hemimelia with Unilateral Radial Club Hand and Constrictive Band on Hand". Journal of Evolution of Medical and Dental Sciences 2014; Vol. 3, Issue 24, June 16; Page: 6721-6725, DOI: 10.14260/jemds/2014/2810

ABSTRACT: Congenital absence of tibia is a rare anomaly and may be total or partial, unilateral or bilateral. Total absence is more frequent than partial. Unilateral absence occurs more often than bilateral, with right limb more commonly affected than the left. In partial defect, almost always the distal end of the bone is affected. In the bilateral cases, there may be total absence on both sides, or total on one side and partial on the other. Males are slightly more commonly affected than the females. Though, the family history is usually negative for congenital abnormalities and other diseases, there is a considerable chance of occurrence of congenital defect of the tibia or of other abnormalities, in near or remote relatives. We report a case of newborn having unilateral tibial hemimelia type 3 with radial club hand and contracture band on the hand.

KEYWORDS: Aplasia, congenital anomaly, tibial defect, tibial hemimelia.

INTRODUCTION: Tibial hemimelia is a very rare disease with an incidence of 1 in 1, 000, 000 live births. ${ }^{[1]}$ It is characterized by deficiency of tibia with relatively intact fibula. It causes marked shortening of the involved extremity with a severe equinovarus deformity.[2] The defect could be either complete or incomplete and occurs either as a solitary disorder, or as a part of more complex malformation syndrome. ${ }^{[1,3]}$ Associated abnormalities include those of the musculoskeletal system of both lower and upper limbs, orofacial part, uro-genital, and cardiovascular systems. The tibial reduction defects were initially classified into 4 major types based only on X-ray findings,[4] however, later expanded to seven major types and five sub-groups according to the therapeutic relevance and considering the importance of cartilaginous anlage [Table 1].[5]

According to the Weber-classification the sequence of the distribution of tibial hemimelia types is as follows: $62 \%$ of cases with type-VII, $15 \%$ with type-III, $6 \%$ with type-I, $6 \%$ with type-V, $5 \%$ with type-II, $3 \%$ with type-IV, and $3 \%$ with type-VI. If the older-classification corresponds to Weber-classification, then the sequence of the distribution would have been as follows: $61 \%$ of cases with type-I, $16 \%$ with type-II, 5\% with type-IV, 3\% with type-III, and $15 \%$ with not otherwise specified. We describe a rare case of unilateral tibial hemimelia that would be classified as type 2 in older-classification, however, type 3 according to the Weber-classification. 
Table 1: Classification of tibial hemimelia:

\begin{tabular}{|c|c|c|c|}
\hline \multicolumn{2}{|c|}{ Newer (Weber) classification } & \multicolumn{2}{|c|}{ Older classification } \\
\hline 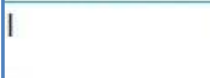 & Tibial hypoplasia & $\mathrm{a}^{\mathrm{a}}$ & $\begin{array}{l}\text { Tibia not seen. Hypoplastic } \\
\text { lower femoral epiphysis }\end{array}$ \\
\hline II & Tibial diastasis & $\mathrm{I}^{\mathrm{b}}$ & $\begin{array}{l}\text { Tibia not seen. Normal } \\
\text { lower femoral epiphysis }\end{array}$ \\
\hline III $\left(\left.I I\right|^{\mathrm{a}}, \mathrm{III}{ }^{\mathrm{b}}\right)$ & Distal tibial aplasia & II & Distal tibia not seen \\
\hline IV $\left(I^{a}, I^{b}\right)$ & $\begin{array}{l}\text { Proximal tibial } \\
\text { aplasia }\end{array}$ & III & Proximal tibia not seen \\
\hline$V\left(V^{a}, V^{b}\right)$ & $\begin{array}{l}\text { Bifocal tibial } \\
\text { aplasia }\end{array}$ & IV & $\begin{array}{l}\text { Diastasis (both proximal } \\
\text { epiphysis and diaphysis are } \\
\text { present but the tibia is short) }\end{array}$ \\
\hline $\mathrm{VI}\left(\mathrm{V} \mathrm{I}^{\mathrm{a}}, \mathrm{V} \mathrm{I}^{\mathrm{b}}\right)$ & $\begin{array}{l}\text { Tibial agenesia } \\
\text { with double fibula }\end{array}$ & & \\
\hline VII $(\mathrm{VII}$, VII') & $\begin{array}{l}\text { Tibial agenesia } \\
\text { with a single fibula }\end{array}$ & & \\
\hline
\end{tabular}

CASE REPORT: A male infant was born at 38 weeks gestation to a 28years old Gravida 3, Para 2, mother with two living issue. Except for fever of 1 week duration (cause not known) during the first trimester, the antenatal period was mostly uncomplicated, without any history of diabetes or hypertension. His mother was a non-smoker, but had undergone chest X-ray once during the first trimester for fever work-up. There was no history of any teratogenic drug intake by the mother including routine multivitamin supplementation also. Antenatal ultrasound was not done. Previous pregnancies were normal without any gross congenital malformations. Parents were of indian descent with no evidence of consanguinity.

He was born by elective caesarean-section because of failed labour. His birth weight was 2.9 kgs (appropriate for gestational age), He did not require any intervention at birth.

On examination, right foot showed equinovarus deformity. The leg segment was internally rotated to $60^{\circ}$ and right hand wrist to radial deviation and constrictive bands in left hand fingers. [Figure1]. The radiological evaluation revealed a normal hip joint. The lower end of femur was normal and patella was present. Right tibia is defective proximally and distally and attached to fibula with a band. Fibula is normal [Figure2]. Systemic examination also did not reveal any abnormality.

Figure 1: Photograph of the newborn showing deformed right lower limb and right radial club hand and constricted bands on left hand.

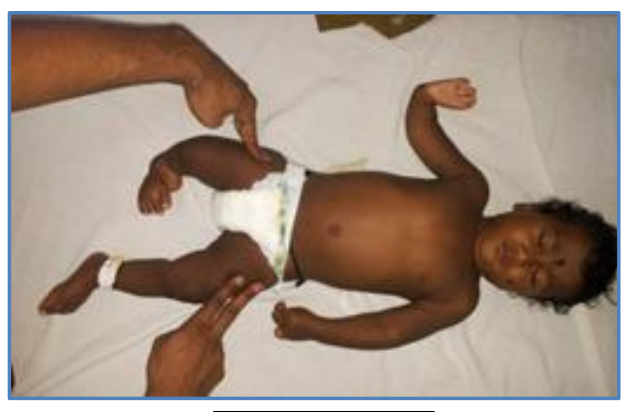

Figure 1 


\section{CASE REPORT}

Figure 2: X-ray showing normal hip joint, normal lower end of femur. Right side tibial defect seen with normal foot.

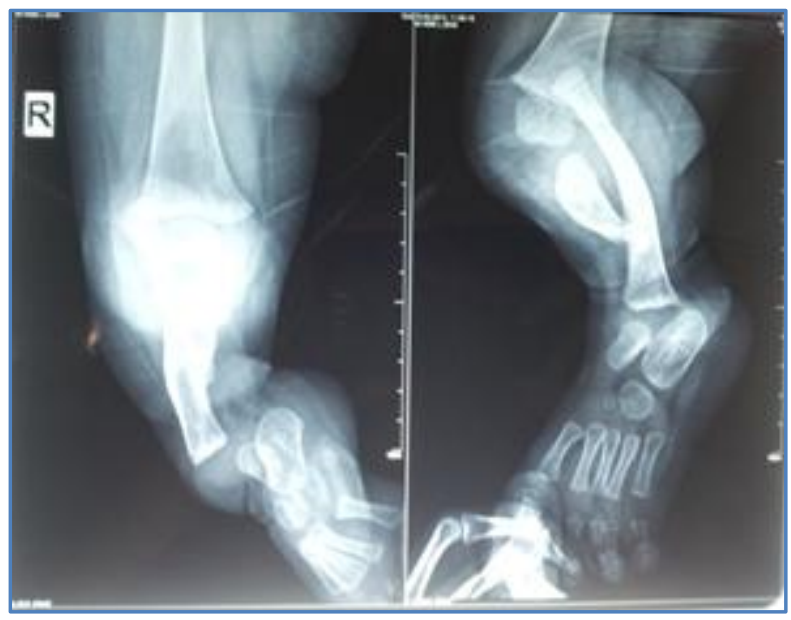

Figure 2

DISCUSSION: The limb defects appear to have a multifactorial etiology, arising from an interaction between environmental influences, teratogenic exposure and the individual's genetic makeup. Tibial hemimelia syndrome, which is a rare autosomal dominant condition, encompasses several types of syndrome, all having a common phenotype of tibial hypoplasia or agenesis and polydactyly.[6] Family history of congenital anomaly of tibia, as well as intra-familial phenotypic variations of the defect in twin pregnancy has been reported.[7,8,9]

The anomalies in which the number of skeletal elements increased arise during the first 7 weeks of intrauterine life. A decrease in the number of skeletal parts may arise after, as well as during, this 7weeks period.[10] The mother of the index case was suffering from pyrexia of unknown origin during the first trimester, and this might have led to the defect by its interaction with some unidentified environmental influences and absent intake of multivitamin supplementation by the mother.[11]

As described above, tibial hemimelia is usually accompanied by other congenital anomalies that include; congenital dislocation of the hip, ectro-, poly-, or syn-dactyly, abnormalities of the musculoskeletal system of both lower and upper limbs, phocomelia, harelip and cleft palate, pseudohermaphroditismn, cryptorchidism, hypospadias etc. One report described a case of tibial hemimelia, femoral bifurcation, cleft lip/palate and cardiovascular anomaly like atrioventricular canal with truncus arteriosus.[12] However, in the index case, though there was right side tibial hemimelia with radial club hand on same side and a constrictive band.

Some cases of tibial hemimelia are genetically transmitted, whereas others are sporadic. Few syndromes such as tibial hemimelia-foot polydactly triphalangeal thumbs syndrome (Werner syndrome), tibial hemimelia diplopodia syndrome, tibial hemimelia-split hand/foot syndrome, tibial hemimelia-micromelia-trigonobrachycephaly syndrome, tibial hemimelia-normal upper limb syndrome and tibial hemimelia-radial agenesis syndrome are considered to be transmitted as autosomal dominant. In others such as, tibial hemimelia-cleft lip/palate syndrome, tibial hemimelia split hand/foot syndrome, an autosomal recessive inheritance is suggested.[13] 
Treatment mainly includes surgical correction of the deformity where possible. Common surgical procedures include disarticulation at Knee, Syme's amputation or Chopart amputation.[2,7] The sooner the amputation is performed, easier and faster the rehabilitation and adaptation to the prosthesis. The absence of the cartilaginous anlage increases the difficulty of the operative procedure. The surgical option for the index case with favorable result would include disarticulation of the knee joint and prosthesis.[2]

\section{REFERENCES:}

1. Fernandez-Palazzi F, Bendahan J, Rivas S. Congenital deficiency of the tibia: A report on 22 cases. J Pediatr Orthop B. 1998; 7: 298-302. [PubMed].

2. Weber M. Congenital leg deformities: Tibial hemimelia. In: Rozbruch SR, Ilizarov S, editors. Limb Lengthening and Reconstruction Surgery. New York: Informa Health Care; 2007. pp. 42947.

3. Matsuyama J, Mabuchi A, Zhang J, Iida A, Ikeda T, Kimizuka M, et al. A pair of sibs with tibial hemimelia born to phenotypically normal parents. J Hum Genet. 2003; 48: 173-6. [PubMed].

4. Henkel HL, Willert HG, Gressmann C. An international terminology for the classification of congenital limb deficiencies. Recommendations of a working group of the international society for prosthetics and orthotics (author>s transl) Arch Orthop Trauma Surg. 1978; 93: 1-19. [PubMed].

5. Weber M. New classification and score for tibial hemimelia. J Child Orthop. 2008; 2: 169-75. [PMC free article] [PubMed].

6. Richieri-Costa A, Ferrareto I, Masiero D, da Silva CR. Tibial hemimelia: Report on 37 new cases, clinical and genetic considerations. Am J Med Genet. 1987; 27: 867-84. [PubMed]

7. Schoenecker PL, Capelli AM, Millar EA, Sheen MR, Haher T, Aiona MD, et al. Congenital longitudinal deficiency of the tibia. J Bone Joint Surg Am. 1989; 71: 278-87. [PubMed]

8. Leite JA, Lima LC, Sampaio ML. Tibial hemimelia in one of the identical twins. J Pediatr Orthop. 2010; 30: 742-5. [PubMed].

9. Dayer R, Ceroni D, Bottani A, Kaelin A. Tibial aplasia-hypoplasia and ectrodactyly in monozygotic twins with a discordant phenotype. J Pediatr Orthop. 2007; 27: 266-9. [PubMed].

10. Frantz CH, Rapids G, O’Rahilly R. Congenital skeletal limb deficiencies. J Bone and Joint Surg.1961; 43A: 1202-24.

11. Botto LD, Erickson JD, Mulinare J, Lynberg MC, Liu Y. Maternal fever, multivitamin use, and selected birth defects: Evidence of interaction? Epidemiology. 2002; 13: 485-8. [PubMed].

12. Erickson RP. Agenesis of tibia with bifid femur, congenital heart disease, and cleft lip with cleft palate or tracheoesophageal fistula: Possible variants of Gollop-Wolfgang complex. Am J Med Genet A.2005; 134: 315-7. [PubMed].

13. Richieri-Costa A. Tibial hemimelia-cleft lip/palate in a Brazilian child born to consanguineous parents. Am J Med Genet. 1987; 28: 325-9. [PubMed]. 


\section{CASE REPORT}

\section{AUTHORS:}

1. Prashanth M.

2. V. Srinivasan

3. J. Satish Kumar

4. D. Kamakshi

\section{PARTICULARS OF CONTRIBUTORS:}

1. Final Year Post Graduate, Department of Plastic Surgery, Sri Ramachandra Medical Center.

2. Professor and HOD, Department of Plastic Surgery, Sri Ramachandra Medical Center.

3. Professor, Department of Plastic Surgery, Sri Ramachandra Medical Center.

4. Professor, Department of Plastic Surgery, Sri Ramachandra Medical Center.

\section{NAME ADDRESS EMAIL ID OF THE CORRESPONDING AUTHOR:}

Dr. Prashanth M, \#E-307, Jasmine Courte, Eta Star Apartments,

Kaattupaakam, Chennai-600056.

E-mail: matturiprashanth@gmail.com

Date of Submission: 02/06/2014.

Date of Peer Review: 03/06/2014.

Date of Acceptance: 09/06/2014.

Date of Publishing: 14/06/2014. 